\title{
Keep an Eye on the Intracranial Pressure, Thanks to the Optic Nerve Sheath Diameter
}

\author{
Alexandre Vagh Weinmann, Charlotte Beaucreux, Kevin Kearns, Clément Dubost \\ Intensive Care Unit, Begin Military Hospital, Saint-Mandé, France
}

\section{Abstract}

Neurological examination on sedated patients is challenging and no gold standard monitoring is currently available. We report the case of a patient deeply sedated for the management of acute respiratory distress syndrome secondary to pneumonia. Delay in awakening led to cerebral exploration by transcranial Doppler (TCD) and measurement of optic nerve sheath diameter (ONSD). Abnormal values of ONSD prompted immediate brain computed tomography scan that confirmed high intracranial pressure (ICP) due to multiple deep parenchymal hematomas. Despite raised ICP, values obtained by TCD were normal, thanks to the persistence of cerebral autoregulation. This case highlights the interest of combining noninvasive techniques for neurological examination, especially for sedated patients.

Keywords: Brain hemodynamics, cerebral Doppler, cerebral monitoring, coma, optic nerve sheath diameter

\section{INTRODUCTION}

Neurological examination of sedated patients is challenging and currently, only a few monitors are available. For patients with elevated intracranial pressure (ICP), the placement of an invasive device (parenchymal probe or intraventricular derivation) remains the gold standard, in order to continuously monitor the ICP. However, for the vast majority of patients without known elevated ICP, there is no gold standard for the monitoring of the sedated brain. In case of critical illness, such as acute respiratory distress syndrome (ARDS), patients may require a deep sedation. When sedation is stopped, the delay of recovery is highly unpredictable and remains an issue. We report the case of a patient deeply sedated for a short period of time who presented a delayed wake up that led us to perform ultrasonographic assessment of the brain. Use of transcranial Doppler (TCD) and measurement of the optic nerve sheath diameter (ONSD) led to the diagnosis of elevated ICP secondary to severe cerebral hemorrhage. Our case highlights the potential interest of noninvasive assessment of the brain in case of delayed wake up for Intensive Care Unit (ICU) patients.

\section{Case Report}

We report the case of a 63-year-old woman with a past medical history of psychiatric disorders without follow-up. The patient

\begin{tabular}{|l|l|}
\hline \multicolumn{3}{|c|}{ Access this article online } \\
\hline Quick Response Code: & Website: \\
& www.ijccm.org \\
\hline
\end{tabular}

was referred to our unit for coma secondary to septic shock. Her story started by a mild traumatic brain injury after a fall and complicated by an aspiration pneumonia, without initial loss of consciousness.

A first computed tomography (CT) was performed which was interpreted as normal, with no sign of bleeding, thin ventricles, and median structure in place.

Pneumonia evolved toward an ARDS that required two sessions of prone positioning associated with deep sedation by midazolam and sufentanil. During this period of induced coma, electrical brain activity was monitored by bispectral index (BIS). Values from the BIS were surprisingly low (25-34) as regard to the low dose of sedative drugs (i.e., midazolam: $0.1-2 \mathrm{mg} / \mathrm{h}$ and sufentanil $2.5-5 \mu \mathrm{g} / \mathrm{h}$ ). However, due to the several known limitations of the BIS in ICU (especially for a patient in prone position), ${ }^{[1]}$ it was decided to maintain a minimal rate of sedation. Improvement in the lung function allowed discontinuation of the sedative drugs, $72 \mathrm{~h}$ after their initiation. Three days after the cessation of sedation, the patient

Address for correspondence: Dr. Clément Dubost, Begin Military Hospital, 69, Avenue de Paris, 94163 Saint-Mandé, France. E-mail: clement.dubost@hotmail.fr

This is an open access journal, and articles are distributed under the terms of the Creative Commons Attribution-NonCommercial-ShareAlike 4.0 License, which allows others to remix, tweak, and build upon the work non-commercially, as long as appropriate credit is given and the new creations are licensed under the identical terms.

For reprints contact: reprints@medknow.com

How to cite this article: Weinmann AV, Beaucreux C, Kearns K, Dubost C. Keep an eye on the intracranial pressure, thanks to the optic nerve sheath diameter. Indian J Crit Care Med 2018;22:460-2. 
recovered a spontaneous ventilation but presented no other sign of waking up. BIS remained low (between 20 and 30), and there were no acute kidney injury or liver failure that could explain a delayed drug's eliminations. ${ }^{[2]}$ Clinical examination found a sluggish reaction to painful stimuli on the left arm and intermediate and reactive pupils.

Ultrasonography was performed to look for impaired brain perfusion or evidence of elevated ICP.

First, TCD was performed bilaterally on the middle cerebral artery (MCA). Measurements of the left MCA were pulsatility Index $=1.09$ and end diastolic velocity $=52.11 \mathrm{~cm} / \mathrm{s}$, whereas right MCA was not identifiable. Those values were interpreted as normal. ${ }^{[3]}$ ONSD measurements were as follows: $7.4 \mathrm{~mm}$ on the right eye and $7.05 \mathrm{~mm}$ on the left eye [Figure 1]. Those values suggested elevated ICP which prompted us to a new brain CT. ${ }^{[4]}$ When ONSD suggested elevated ICP, immediate treatment was started to try to control the ICP: osmotherapy and blood pressure elevation. While waiting for the CT san, preventive measures were applied: head elevation, control of temperature, carbon dioxide, and glycemia. It revealed multiple deep parenchymal hematomas, not suggestive of traumatic origin, bilateral cerebellar ischemia, and diffuse cerebral edema with brain coning [Figure 2]. Emergent treatment was started in order to optimize brain perfusion. Despite optimal treatment, the evolution was rapidly unfavorable toward a brain death on day 8 of management. TCD demonstrated a backflow in MCA and brain death was confirmed by two electroencephalograms with no electrical activity.

\section{Discussion}

Delayed awakening is often described in ICU but not precisely defined. ${ }^{[2]}$ The main explanation is a delayed metabolism secondary to liver or renal failure. ${ }^{[2]}$ None of those conditions were present in the present case and international recommendations on daily interruption of sedative drugs were respected. ${ }^{[5]}$ However, the BIS values remained low, even after cessation of all sedative drugs. Clinical examination was not

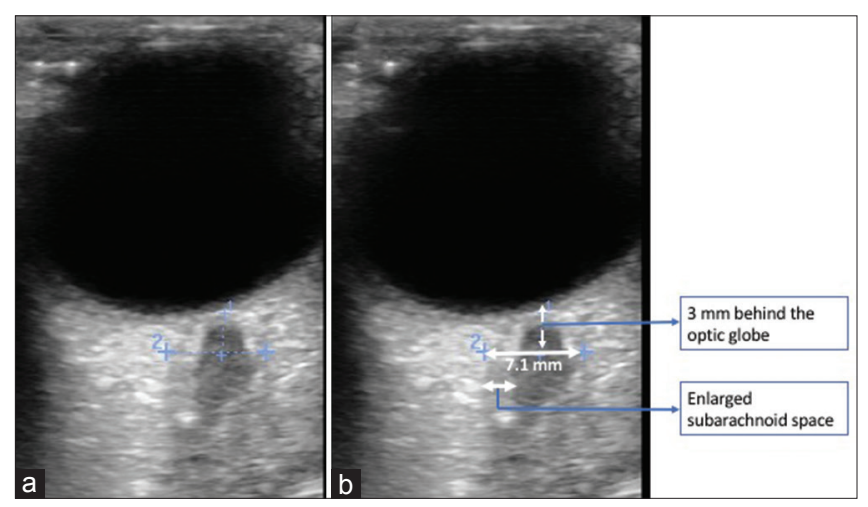

Figure 1: Ultrasonographic measurement of the right optic nerve sheath diameter. (a) row image (b) explains how measurements are made with marks at $30 \mathrm{~mm}$ behind the ocular globe and transversal measurement of the optic nerve sheath, from one dura mater to the other one informative, but bedside ultrasonographic assessment allowed a diagnosis of elevated ICP and yielded to immediate brain CT.

TCD revealed a maintained CPP despite an increase of all the values of the ONSD ( 2 measurements per eye), suggesting raised ICP. In the course of elevated ICP secondary to brain trauma, flow velocity remains normal at the beginning of ICP rise because of a "tray of self-regulation," where cerebral perfusion rate (CPR) is stable at a large CCP interval $(50-150 \mathrm{mmHg}){ }^{[3]}$ This stability is obtained by reflex vasoconstriction of cerebral arterioles, which keep the CPR constant. This is one of the main limitations of the TCD that intensivists must be aware of. On the contrary, measurement of the ONSD allows a noninvasive estimation of the ICP. The optical nerve envelop is in continuity with the dura mater and the anterior portion of the optical nerve is thin and distensible because it is surrounded by periocular fat. Thus, an increase in cerebrospinal fluid pressure will be transmitted around the optical nerve, increasing its diameter ${ }^{[6]}$ A meta-analysis published in 2011 gathered data from 372 patients included in six studies. ${ }^{[7]}$ The authors found a pooled sensitivity of 0.90 and a pooled specificity of 0.85 .

If ONSD had not been evaluated, ICH may have remained unknown. This highlights the interest of noninvasive techniques and the importance of combining several methods of measurement. In a case where intracerebral complication is very likely, it seems necessary not to stop the examination at a normal TCD and carry on with ONSD measurements. In the expectation of an accurate brain monitor, TCD and ONSD, used in conjunction, are the best ways to evaluate brain hemodynamics. ONSD measurement offers the possibility to noninvasively assess the ICP. It remains a punctual assessment but is free of danger for the patient, whereas invasive ICP measurement exposes patients to infections, hemorrhages, and technical difficulties, fortunately rare but serious. ${ }^{[8]}$ ONSD measurement should be employed every time the benefit/risk balance for invasive ICP is unfavorable.

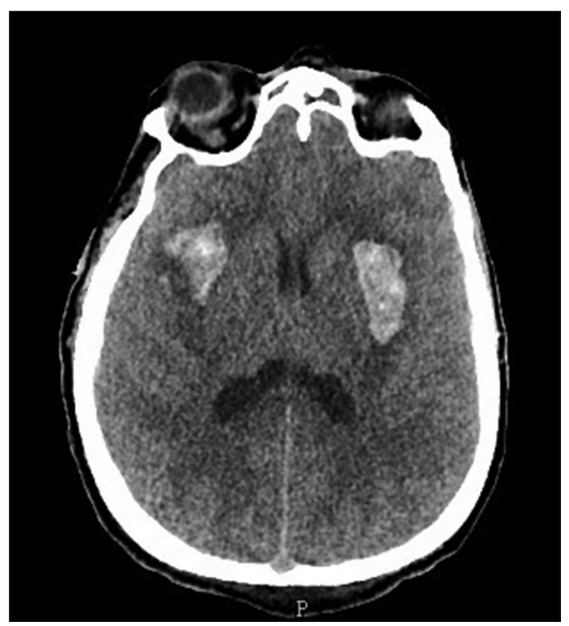

Figure 2: Computed tomography scan of the patient on day 5 demonstrating bilateral intracranial hematomas 


\section{Declaration of patient consent}

The authors certify that they have obtained all appropriate patient consent forms. In the form the patient(s) has/have given his/her/their consent for his/her/their images and other clinical information to be reported in the journal. The patients understand that their names and initials will not be published and due efforts will be made to conceal their identity, but anonymity cannot be guaranteed.

\section{Financial support and sponsorship}

Nil.

\section{Conflicts of interest}

There are no conflicts of interest.

\section{RefERENCES}

1. Nasraway SA Jr., Wu EC, Kelleher RM, Yasuda CM, Donnelly AM. How reliable is the bispectral index in critically ill patients? A prospective, comparative, single-blinded observer study. Crit Care Med 2002;30:1483-7.
2. McKenzie CA, McKinnon W, Naughton DP, Treacher D, Davies G, Phillips GJ, et al. Differentiating midazolam over-sedation from neurological damage in the Intensive Care Unit. Crit Care 2005;9:R32-6.

3. Czosnyka M, Matta BF, Smielewski P, Kirkpatrick PJ, Pickard JD. Cerebral perfusion pressure in head-injured patients: A noninvasive assessment using transcranial Doppler ultrasonography. J Neurosurg 1998;88:802-8.

4. Geeraerts T, Merceron S, Benhamou D, Vigué B, Duranteau J. Non-invasive assessment of intracranial pressure using ocular sonography in neurocritical care patients. Intensive Care Med 2008;34:2062-7.

5. Kress JP, Pohlman AS, O'Connor MF, Hall JB. Daily interruption of sedative infusions in critically ill patients undergoing mechanical ventilation. N Engl J Med 2000;342:1471-7.

6. Dubost C, Motuel J, Geeraerts T. Non-invasive evaluation of intracranial pressure: How and for whom? Ann Fr Anesth Reanim 2012;31:e125-32.

7. Dubourg J, Javouhey E, Geeraerts T, Messerer M, Kassai B. Ultrasonography of optic nerve sheath diameter for detection of raised intracranial pressure: A systematic review and meta-analysis. Intensive Care Med 2011;37:1059-68.

8. Münch E, Weigel R, Schmiedek P, Schürer L. The Camino intracranial pressure device in clinical practice: Reliability, handling characteristics and complications. Acta Neurochir (Wien) 1998;140:1113-9. 